\title{
Inhibition of proliferation and migration of melanoma cells by ketoconazole and Ganoderma immunomodulatory proteins
}

\author{
CHUN-TE LU ${ }^{1,2}$, PUI-YING LEONG ${ }^{1,3}$, TING-YI HOU ${ }^{1}$, YU-TING KANG ${ }^{1}$, YAN-CHENG CHIANG ${ }^{1,4}$, \\ CHIH-TING HSU ${ }^{1}$, YAN-DE LIN ${ }^{5}$, JIUNN-LIANG KO ${ }^{1,6^{*}}$ and YU-PING HSIAO ${ }^{1,4^{*}}$ \\ ${ }^{1}$ Institute of Medicine, School of Medicine, Chung Shan Medical University, Taichung 40201; \\ ${ }^{2}$ Division of Plastic and Reconstructive Surgery, Department of Surgery, Taichung Veterans General Hospital, \\ Taichung 40705; Departments of ${ }^{3}$ Rheumatology, ${ }^{4}$ Dermatology, ${ }^{5}$ Medical Laboratory and Biotechnology, and \\ ${ }^{6}$ Medical Oncology and Chest Medicine, Chung Shan Medical University Hospital, Taichung 40201, Taiwan, R.O.C.
}

Received February 8, 2018; Accepted March 7, 2019

DOI: $10.3892 / \mathrm{ol} .2019 .10355$

\begin{abstract}
Ketoconazole, an antifungal agent, has been used to inhibit hormone synthesis in types of prostate and breast cancer. Immunomodulatory proteins of Ganoderma microsporum (GMI) inhibit the tumor necrosis factor- $\alpha$ - and epidermal growth factor-induced metastatic ability of lung cancer cells. Cutaneous malignant melanoma is a highly invasive and metastatic skin cancer. However, to the best of our knowledge, there is limited understanding regarding the effects of ketoconazole and GMI on melanoma. The current study aimed to investigate the inhibitory effects of GMI combined with ketoconazole on melanoma survival and metastasis. The effects of GMI combined with ketoconazole on the viability, migration and protein expression of melanoma cells were determined by MTT assay, Boyden chamber assay and western blot analysis, respectively. The expression of monocyte chemoattractant protein-1 (MCP-1) was investigated by enzyme-linked immunoabsorbent assay. The present results indicate that ketoconazole enhances the GMI-induced decrease in proliferation and migration of A375.S2 melanoma cells in a concentration-dependent manner. Ketoconazole was identified to reduce the level of GMI-induced phosphorylated-adenosine monophosphate-activated protein kinase (p-AMPK)- $\alpha$ and autophagy; however, ketoconazole did not affect $\mathrm{p}$-AMPK- $\beta$ levels in A375.S2 cells. In addition, ketoconazole and dorsomorphin dihydrochloride, an AMPK inhibitor, were revealed
\end{abstract}

Correspondence to: Professor Jiunn-Liang Ko or Dr Yu-Ping Hsiao, Institute of Medicine, School of Medicine, Chung Shan Medical University, Section 1, 110 Chien-Kuo North Road, Taichung 40201, Taiwan, R.O.C.

E-mail: jlko@csmu.edu.tw

E-mail: missyuping@gmail.com

*Contributed equally

Key words: ketoconazole, Ganoderma microsporum, adenosine monophosphate-activated protein kinase, monocyte chemoattractant protein-1, melanoma to reduce MCP-1 secretion in A375.S2 cells. In summary, the present study revealed that ketoconazole enhances GMI-inhibited proliferation and migration of A375.S2 melanoma cancer cells, and inhibits the secretion of MCP-1.

\section{Introduction}

Ketoconazole, a cytochrome P450 inhibitor with antifungal effects, has been reported to exhibit anticancer effects, including increased plasma levels of cytotoxic fenretinide and enhanced intratumoral apoptosis in neuroblastoma (1). In addition, a combination of venetoclax with ketoconazole has been reported to exhibit significant therapeutic effects for patients with chronic lymphocytic leukemia (2). Furthermore, ketoconazole is a second-line hormonal agent in castration-resistant prostate cancer as it reduces androgen biosynthesis (3).

Immunomodulatory protein cloned from Ganoderma microsporum (GMI) contains 110 amino acids. Overall, $83 \%$ homology exists between fungal immunomodulatory proteins from Ganoderma tsugae and GMI in the alignment of amino acid sequences (4). It has been demonstrated in A549 cells that GMI inhibits tumor necrosis factor $\alpha$-induced matrix metalloproteinase 9-mediated migration and invasion (5). A number of signaling pathways have been reported to be affected by GMI in the treatment of various cancer types. In non-small-cell lung cancer, oral administration of GMI induces activation of $\mathrm{Ca}^{2+}$-dependent pathways, which is associated with a decrease in cytosolic p53 (4). Chiu et al (6) proposed that induction of autophagy by GMI destroys multiple drug resistance mechanisms via Akt/mammalian target of rapamycin inhibition in the treatment of lung cancer.

In our previous study, GMI was identified to enhance cisplatin-induced apoptosis via the autophagy/caspase-7 pathway in lung cancer. The effects of GMI with low-dose cisplatin indicate that GMI can serve as an adjuvant of cisplatin in the treatment of lung cancer (7). Recently, GMI has been demonstrated to induce oral cancer stem cell-elicited tumor regression via blockage of the interleukin-6/signal transducer and activator of transcription 3 signaling pathway (8).

Adenosine monophosphate-activated protein kinase (AMPK) is an energy sensor activated by metabolic stress to 
maintain cellular energy homeostasis (9). AMPK is activated by the upstream kinase liver kinase B1 and is negatively regulated by phosphorylation of the heterodimeric AMPK (9). Studies regarding AMPK activation and inhibition of migration or invasion have produced controversial results. Inhibition of AMPK results in increased migration of pancreatic cancer cells (10). C-X-C motif chemokine ligand 12 prevents pancreatic ductal adenocarcinoma metastasis via phosphorylated (p)-AMPK activation (10). Ginkgolic acid, a phenolic acid extracted from ginkgo fruit, inhibits migration and invasion by inducing AMPK activation in colon cancer cells (11).

Monocyte chemoattractant protein-1 (MCP-1; also termed CCL2) is a major chemokine that induces infiltration and migration of macrophages and monocytes (12). Both MCP-1 and its receptor CCR2 have been reported to be induced and involved in various types of tumor. Macrophages and microglia produce MCP-1, which is critical for recruiting both regulatory $\mathrm{T}$ cells and myeloid-derived suppressor cells in the glioma microenvironment (13). Blockage of the MCP-1-CCR2 complex in combination with radiotherapy improves radiotherapeutic efficacy in pancreatic ductal adenocarcinoma (12).

To the best of our knowledge, there is limited understanding regarding the effects of ketoconazole, alone and in combination with GMI, on melanoma. The aim of the current study was to investigate the inhibitory effects of GMI combined with ketoconazole on melanoma survival and metastasis. Results of the present study revealed that a combination of GMI and ketoconazole can inhibit the proliferation and migration of melanoma and reduce the level of secreted MCP-1.

\section{Materials and methods}

Cell line and chemicals. A375.S2 human melanoma cells and Hs68 fibroblast were purchased from the Food Industry Research and Development Institute (Hsinchu, Taiwan). A375.S2 cells were incubated in minimum essential medium (MEM) (Gibco; Thermo Fisher Scientific, Inc.) supplemented with $2 \mathrm{mM}$ L-glutamine, $0.1 \mathrm{mM}$ non-essential amino acids, $1.5 \mathrm{~g} / 1$ sodium bicarbonate and $1.0 \mathrm{mM}$ sodium pyruvate. The medium also contained $10 \%$ heat-inactivated fetal bovine serum (FBS) (Gibco; Thermo Fisher Scientific, Inc) and antibiotics, including $100 \mathrm{U} / \mathrm{ml}$ penicillin and $100 \mu \mathrm{g} / \mathrm{ml}$ streptomycin. The cells were cultured in an incubator with a humidified atmosphere of $5 \% \mathrm{CO}_{2}$ at $37^{\circ} \mathrm{C}$.

MTT was purchased from Sigma-Aldrich (Merck KGaA, Darmstadt, Germany). Dorsomorphin dihydrochloride (catalog no. 3093) and ketoconazole (catalog no. 1103) were obtained from Tocris Bioscience (Bristol, UK).

Production of GMI protein. GMI, kindly provided by Mycomagic Biotechnology Co., Ltd. (Taipei, Taiwan), was expressed and generated from G. microsporum. GMI was cloned and expressed as described previously (4).

Cytotoxicity assay. A375.S2 cells grown to $80 \%$ confluency were washed twice with PBS and trypsinized with $1 \mathrm{ml} 0.25 \%$ trypsin- $0.03 \%$ EDTA. The cells were then seeded at a density of $5 \times 10^{3}$ cells/well into 96 -well microtiter tissue culture plates. The seeded plates were incubated for $24 \mathrm{~h}$ at $37^{\circ} \mathrm{C}$ in $5 \% \mathrm{CO}_{2}$. The original media was then aspirated and fresh media containing varying concentrations of GMI $(0,0.3,0.6$ and $1.2 \mu \mathrm{M})$ and/or ketoconazole $(0,10$ and $20 \mu \mathrm{M})$ was added to the 96 -well plates, followed by incubation at $37^{\circ} \mathrm{C}$ for 24 or $48 \mathrm{~h}$. A cytotoxicity assay was then performed using MTT and dimethyl sulfoxide was used to dissolve the purple formazan. The absorbance was recorded at a wavelength of $570 \mathrm{~nm}$ using a microtiter plate reader.

Western blot analysis. A375.S2 cell lysates were extracted by RIPA buffer (catalog no., 9806; Cell Signaling Technology, Inc.). The protein concentrations were determined by Bio-Rad Protein Assay (catalog no. 5000006; Bio-Rad Laboratories, Inc.). Total lysates $(50 \mu \mathrm{g})$ were loaded per lane and resolved by $10 \%$ SDS-PAGE, and transferred onto polyvinylidene difluoride (PVDF) membranes using a transblot system (Bio-Rad Laboratories, Inc.). The PVDF membranes were then incubated with blocking buffer $[0.01 \mathrm{M}$ Tris- $\mathrm{HCl}$ buffer (pH 7.5), $0.1 \mathrm{M} \mathrm{NaC}, 0.1 \%$ Tween-20 and 3\% BSA] for $1 \mathrm{~h}$ at $25^{\circ} \mathrm{C}$ and washed. Subsequently, the membranes were incubated overnight at $4^{\circ} \mathrm{C}$ with the following primary antibodies: Anti-phosphorylated (p)-adenosine monophosphate-activated protein kinase (AMPK) $\alpha$ (catalog no. 2535; dilution 1:500), anti-AMPK $\alpha$ (catalog no. 2603; dilution 1:1,000), anti-p-AMPK $\beta 1$ (catalog no. 4181; dilution 1:1,000), anti-AMPK $\beta 1 / 2$ (catalog no. 4150; dilution 1:1,000), anti-p-acetyl-CoA carboxylase (ACC; catalog no. 3661; dilution 1:500), anti-dihydrosphingosine 1-phosphate phosphatase LCB3 (LC3B; catalog no. 3868; dilution 1:2,000), anti-survivin (catalog no. 2808; dilution 1:1,000), anti- $\beta$-actin (catalog no. 3700; dilution 1:5,000) and anti-ACC (catalog no. 3676; dilution 1:1,000), all obtained from Cell Signaling Technology, Inc. (Danvers, MA, USA). Primary antibodies were diluted to the appropriate volume in blocking buffer. The membranes were then incubated with a horseradish peroxidase-conjugated anti-rabbit secondary antibody (catalog no. 7074; dilution 1:5,000) for $1 \mathrm{~h}$ at room temperature. Immunoreactive bands were visualized using an enhanced chemiluminescent system (NEN Life Science Products, Inc., Boston, MA, USA). The band density was analyzed by ImageJ version $1.34 \mathrm{e}$ software (National Institutes of Health).

Assay for MCP-1 chemokines. A375.S2 cells ( $5 \times 10^{5}$ cells) were plated onto a $6 \mathrm{~cm}$ dish (Nalge Nunc International, Penfield, NY, USA) with or without $40 \mu \mathrm{M}$ dorsomorphin dihydrochloride following treatment with GMI $(0$ and $0.6 \mu \mathrm{M})$ and/or ketoconazole $(0$ and $20 \mu \mathrm{M})$ for $48 \mathrm{~h}$ incubated at $37^{\circ} \mathrm{C}$. The conditioned media were assayed for MCP-1 secretion by solid-phase enzyme-linked immunoabsorbent assay (ELISA) using a MCP-1/CCL2 Human Uncoated ELISA kit (catalog no. 88-7399; eBioscience; Thermo Fisher Scientific, Inc., Waltham, MA, USA), according to the manufacturer's protocol.

Boyden chamber assay. Cell migration assays were performed using modified Boyden chambers. MEM with 10\% FBS was added to the lower chamber. A375.S2 cells were pretreated with GMI $(0,0.6$, and $1.2 \mu \mathrm{M})$ for $24 \mathrm{~h}$ at $37^{\circ} \mathrm{C}$ and collected, 
followed by resuspension at a density of $2 \times 10^{5}$ cells/well in MEM with $0.5 \%$ FBS in the upper chamber. Following incubation for $24 \mathrm{~h}$, cells on the membrane were fixed with methanol and stained with 20\% Giemsa solution (Merck KGaA) for $2 \mathrm{~h}$ at $25^{\circ} \mathrm{C}$. The stained cells were then counted under a light microscope (magnification, $\mathrm{x} 100$ ).

Apoptosis assay. The apoptosis assay was performed by Annexin $\mathrm{V}$ and propidium iodide staining using the FITC Annexin V Apoptosis Detection kit (catalog no. 556547; BD Biosciences, San Jose, CA, USA). Following GMI (0, 0.6 and $1.2 \mu \mathrm{M})$ and ketoconazole $(0,10$ and $20 \mu \mathrm{M})$ treatment for $24 \mathrm{~h}$ at $37^{\circ} \mathrm{C}, \mathrm{A} 375 . \mathrm{S} 2$ cells were trypsinized and stained with Annexin $\mathrm{V}$ and propidium iodide solution, according to the manufacturer's protocol. Following staining, the cells were analyzed using a flow cytometer and CellQuest 5.1 software (BD Biosciences).

Statistical analysis. Comparisons between two groups were performed by one-way analysis of variance followed by Tukey's post hoc test using Predictive Analytics 18 software (IBM Corporation). All data are presented as the mean \pm standard deviation. Each experiment was performed in triplicate. $\mathrm{P}<0.05$ was considered to indicate a statistically significant difference.

\section{Results}

Ketoconazole enhances the cytotoxic effect of GMI in melanoma cancer cells. The cell viability of A375.S2 cells treated with varying concentrations of ketoconazole and GMI for 24 and $48 \mathrm{~h}$ was analyzed by MTT assay. GMI was identified to mediate cytotoxicity in A375.S2 cells. As presented in Fig. 1A and B, ketoconazole enhanced GMI-induced inhibition of cell viability in a concentration-dependent manner in A375.S2 cells. Using Annexin V/propidium iodide staining, it was revealed that GMI induced apoptosis in a dose-dependent manner and ketoconazole increased GMI-activated apoptosis in A375.S2 cells (Fig. 1C). In addition, it was identified that treatment with 0.3 and $0.6 \mu \mathrm{M}$ GMI did not decrease cell viability in human skin fibroblast Hs68 cells (data not shown), which suggests ketoconazole does not induce cytotoxicity in Hs 68 cells.

Ketoconazole enhances GMI-induced inhibition of A375S2 cells migration. The effects of ketoconazole on GMI-inhibited cell migration were then investigated using a modified Boyden chamber assay to quantify the migratory potential of A375.S2 cells. The results revealed that GMI induced a dose-dependent decrease in migration (Fig. 2A). As presented in Fig. 2B, following treatment with $0.6 \mu \mathrm{M}$ GMI the proportion of migrated cells reduced to $39 \%$ and with $1.2 \mu \mathrm{M}$ GMI with or without $20 \mu \mathrm{M}$ ketoconazole the proportion of migrated cells was $<20 \%$. Ketoconazole induced a dose-dependent decrease in GMI-inhibited migration to $<15 \%$. Furthermore, low-toxic concentrations $(0.3 \mu \mathrm{M})$ of GMI and ketoconazole were used for a migration assay. GMI $(0.3$ and $0.6 \mu \mathrm{M})$ significantly inhibited the migratory ability of A375.S2 cells (Fig. 2C and D). This indicates that GMI inhibits the migratory ability of A375. $\mathrm{S} 2$ cells in a cytotoxic-independent manner.
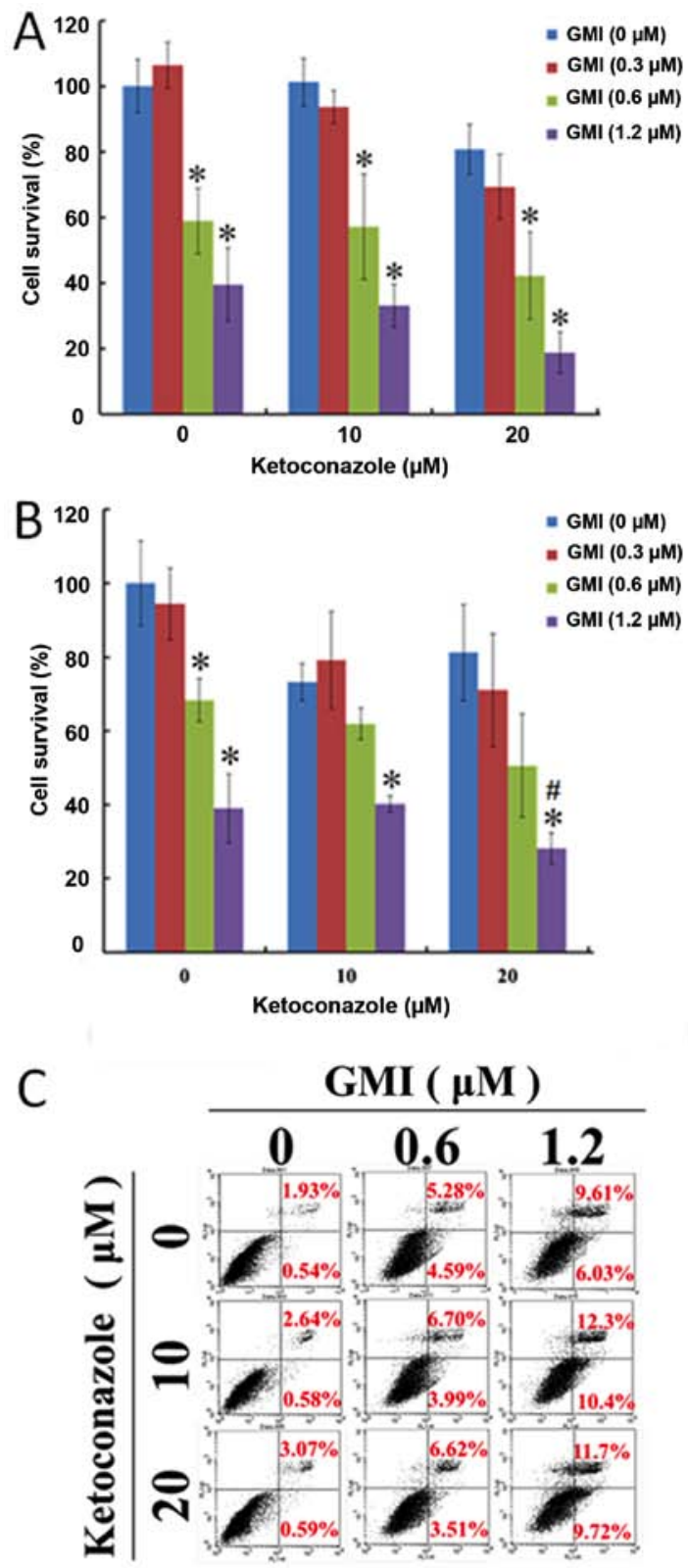

Figure 1. Effects of ketoconazole combined with GMI in A375.S2 cells A375.S2 cells were treated with various concentrations of ketoconazole $(0$, $5,10$ and $20 \mu \mathrm{M})$ and $\operatorname{GMI}(0,0.3,0.6$ and $1.2 \mu \mathrm{M})$ for $(\mathrm{A}), 24$ or $(\mathrm{B}) 48 \mathrm{~h}$, and cell survival was analyzed by MTT assay. (C) A375.S2 cells were treated with GMI and ketoconazole for $24 \mathrm{~h}$ and apoptotic cells were detected by Annexin V/propidium iodide staining and flow cytometry. Data are presented as the mean \pm standard deviation. ${ }^{*} \mathrm{P}<0.05$ vs. $0 \mu \mathrm{M}$ GMI; ${ }^{~} \mathrm{P}<0.05$ vs. $1.2 \mu \mathrm{M}$ GMI. GMI, Ganoderma microsporum.

Ketoconazole reduces GMI-activated $p$-AMPK $\alpha$ and autophagy but does not affect p-AMPK 1 in A375.S2 cells. To investigate the effects of ketoconazole and GMI on p-AMPK signaling and autophagy, the expression levels of dihydrosphingosine 1-phosphate phosphatase LCB3 (LC3B), p-AMPK $\alpha, p-A M P K \beta 1$ and downstream p-ACC were measured by western blot analysis. Activation of AMPK inhibits the metastatic potential of tumor cells by reducing the activity of molecules associated with the ERK signaling pathway, particularly berberine and 5-aminoimidazole-4-ca rboxamide-1- $\beta$-d-ribofuranoside (14). To investigate which p-AMPK isoform is regulated by GMI, the expression levels 

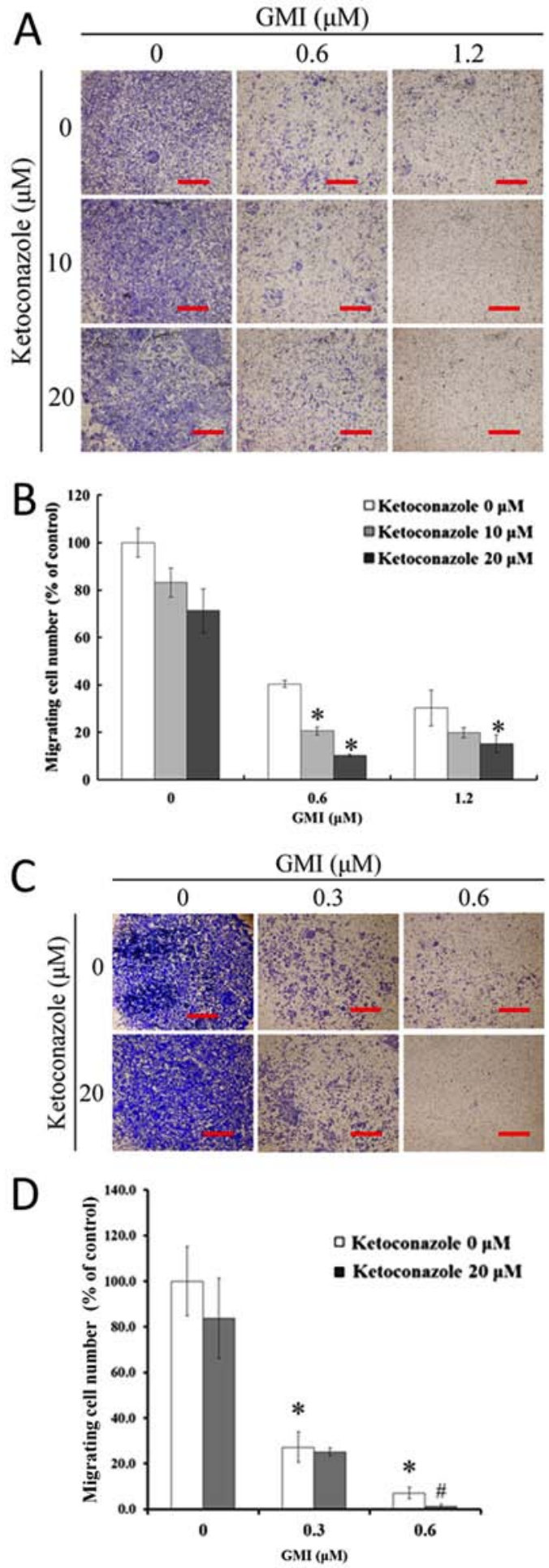

Figure 2. GMI inhibits the migration of A375.S2 cells in vitro. (A) A375. S2 cells were treated with various concentrations of ketoconazole $(0,10$ or $20 \mu \mathrm{M})$ and GMI $(0,0.6$ or $1.2 \mu \mathrm{M})$ for $16 \mathrm{~h}$. The migratory capacity of the cells was then determined in vitro by a Boyden chamber assay. Scale bar, $100 \mu \mathrm{m}$. (B) The numbers of migrated cells were quantified relative to the control. (C) A375.S2 cells were treated with ketoconazole (0 or $20 \mu \mathrm{M})$ and GMI $(0,0.3$ or $0.6 \mu \mathrm{M})$ for $16 \mathrm{~h}$. The migratory capacity of the cells was then determined in vitro by a Boyden chamber assay. (D) The numbers of migrated cells were quantified relative to the control. Data are presented as the mean \pm standard deviation. GMI, Ganoderma microsporum. ${ }^{*} \mathrm{P}<0.05$ vs. $0 \mu \mathrm{M}$ GMI; ${ }^{\# P}<0.05$ vs. $1.2 \mu \mathrm{M}$ GMI.

of p-AMPK $\alpha, \mathrm{p}$-AMPK $\beta 1$ and $\mathrm{p}$-ACC were determined. Treatment with $0.6 \mu \mathrm{M}$ GMI for $6 \mathrm{~h}$ increased p-AMPK $\alpha$ and

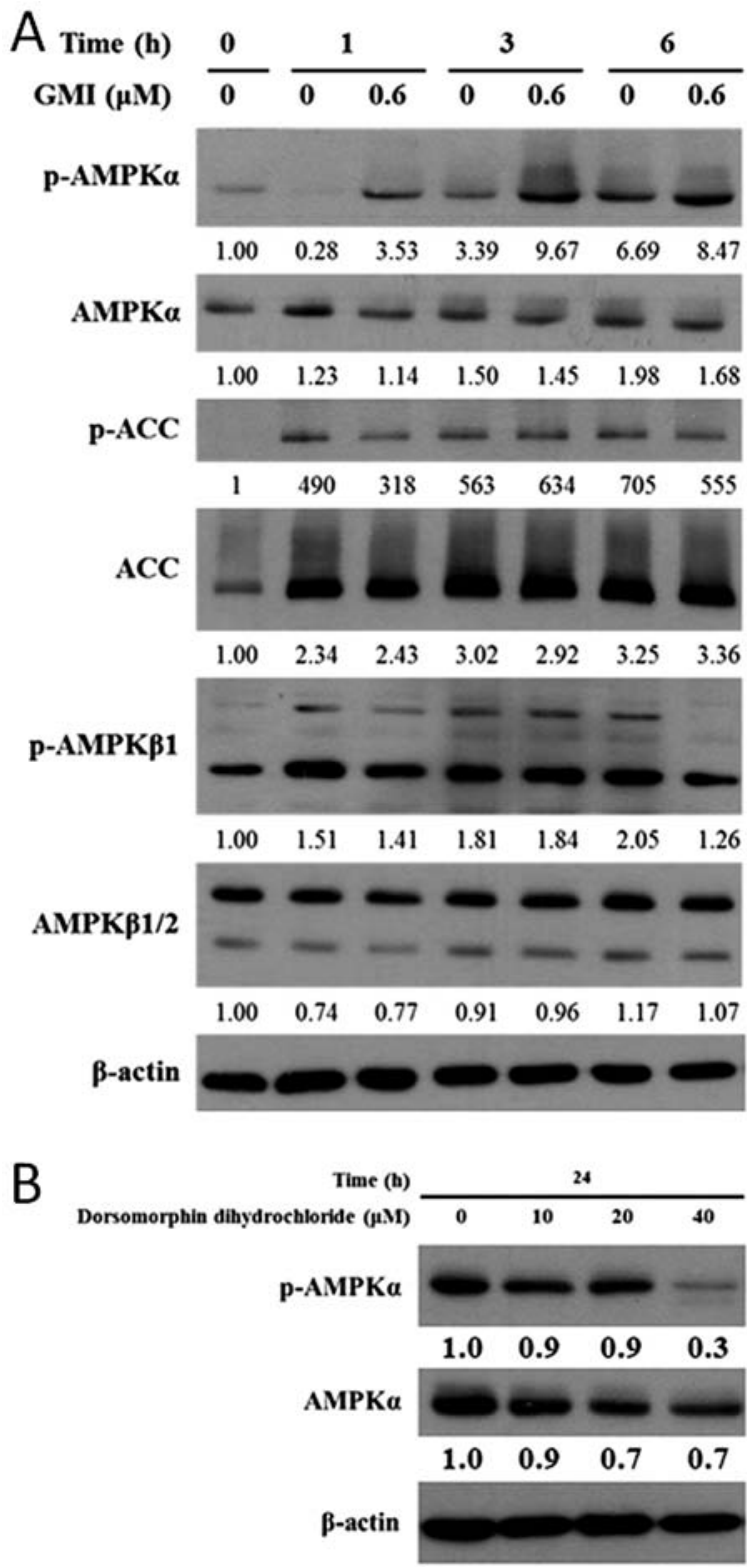

Figure 3. Effects of GMI and dorsomorphin dihydrochloride on the protein expression levels of proteins associated with the AMPK signaling pathway. (A) A375 cells were treated with GMI $(0$ or $0.6 \mu \mathrm{M})$ for $0,1,3$ or $6 \mathrm{~h}$. (B) A375.S2 cells were treated with various concentrations of dorsomorphin dihydrochloride for $24 \mathrm{~h}$. GMI, Ganoderma microsporum; AMPK, adenosine monophosphate-activated protein kinase; $\mathrm{p}-$, phosphorylated; ACC, acetyl-CoA carboxylase.

p-ACC expression levels but did not affect the expression level of p-AMPK $\beta 1$ (Fig. 3A). The AMPK inhibitor dorsomorphin dihydrochloride is a cell-permeable compound that inhibits AMPK kinases, vascular endothelial growth factor receptor 2 and activin-like kinase 2 (9). In the present study, treatment with $40 \mu \mathrm{M}$ dorsomorphin dihydrochloride for $24 \mathrm{~h}$ reduced the expression level p-AMPK $\alpha$ (Fig. 3B).

As presented in Fig. 4A, treatment with GMI for $48 \mathrm{~h}$ increased the expression levels of LC3B and p-AMPK in A375.S2 cells. Treatment with ketoconazole and GMI for $48 \mathrm{~h}$ decreased the expression level of survivin but did not affect the expression of LC3B, p-AMPK or p-ACC. In addition, treatment with $40 \mu \mathrm{M}$ dorsomorphin dihydrochloride inhibited GMI-induced p-AMPK expression. The LC3B expression 


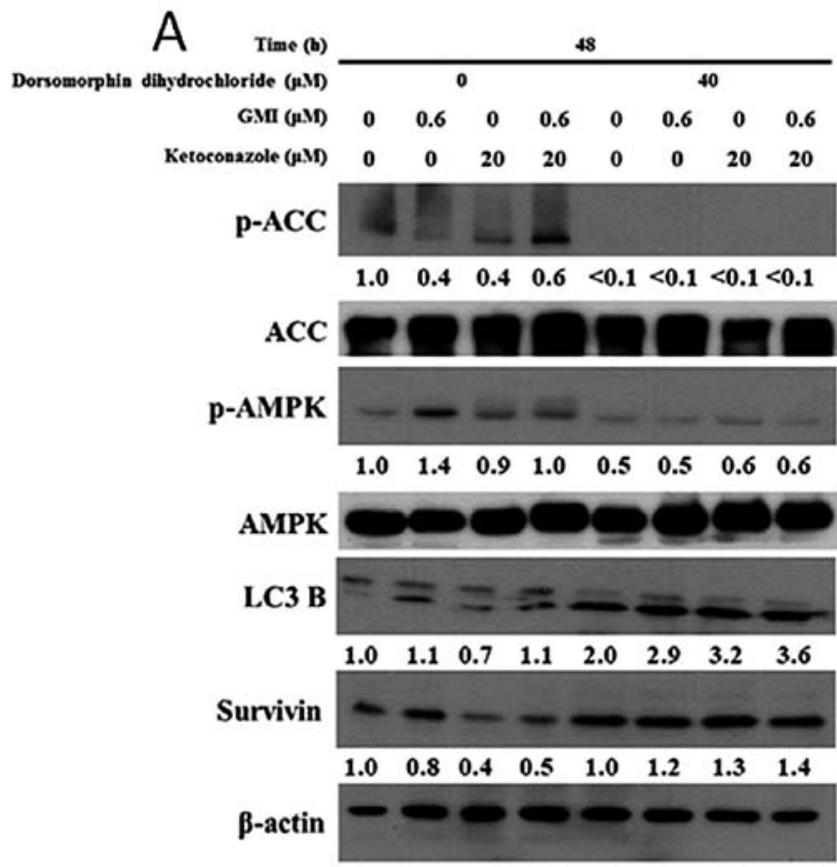

B

\begin{tabular}{rcccc} 
Time (h) & \multicolumn{4}{c}{3} \\
\cline { 2 - 5 } GMI $(\boldsymbol{\mu M})$ & 0 & 0.6 & 0 & 0.6 \\
Ketoconazole $(\boldsymbol{\mu M})$ & 0 & 0 & 20 & 20 \\
p-AMPK & & & & \\
& 1.0 & 1.5 & 1.2 & 1.5 \\
AMPK & & & & \\
\hline $\boldsymbol{\beta}$-actin & & & & \\
\cline { 2 - 4 } & & & &
\end{tabular}

Figure 4. Effects of GMI and dorsomorphin dihydrochloride on the protein expression levels of proteins associated with cell death and the AMPK signaling pathway. (A) A375.S2 cells were pretreated with $40 \mathrm{mM}$ dorsomorphin dihydrochloride for $1 \mathrm{~h}$ and then treated with ketoconazole $(0$ or $20 \mu \mathrm{M})$ combined with GMI $(0$ or $0.6 \mu \mathrm{M})$ for $48 \mathrm{~h}$. The expression levels of p-AMPK, AMPK, p-ACC, ACC, LC3B (LC3B-I and LC3B-II) and survivin were measured by western blot analysis. GMI and ketoconazole increased the expression level of LC3B and reduced the expression of survivin. (B) A375.S2 cells were treated with ketoconazole $(0$ or $20 \mu \mathrm{M})$ combined with GMI ( 0 or $0.6 \mu \mathrm{M}$ ) for $3 \mathrm{~h}$. The expression levels of p-AMPK, AMPK and $\beta$-actin were then measured by western blot analysis. GMI, Ganoderma microsporum; AMPK, adenosine monophosphate-activated protein kinase; p-, phosphorylated; ACC, acetyl-CoA carboxylase; LC3B, dihydrosphingosine 1-phosphate phosphatase LCB3.

level increased following treatment with dorsomorphin dihydrochloride. In addition, dorsomorphin dihydrochloride inhibited the ketoconazole and GMI-induced decrease in survivin expression level. Furthermore, treatment with GMI and ketoconazole for $3 \mathrm{~h}$ increased the expression level of activated p-AMPK (Fig. 4B), which suggests that treatment for a short time period can increase AMPK activity.

Ketoconazole and dorsomorphin dihydrochloride reduce MCP-1 secretion in A375.S2 cells. In addition, MCP-1 is an important chemokine that attracts macrophages to tumors (15). The present study used ELISA to evaluate the secretion of MCP-1 following treatment with GMI and ketoconazole. Ketoconazole was identified to significantly reduce the level of MCP-1, whereas 0.6 $\mu \mathrm{M}$ GMI did not affect the level of

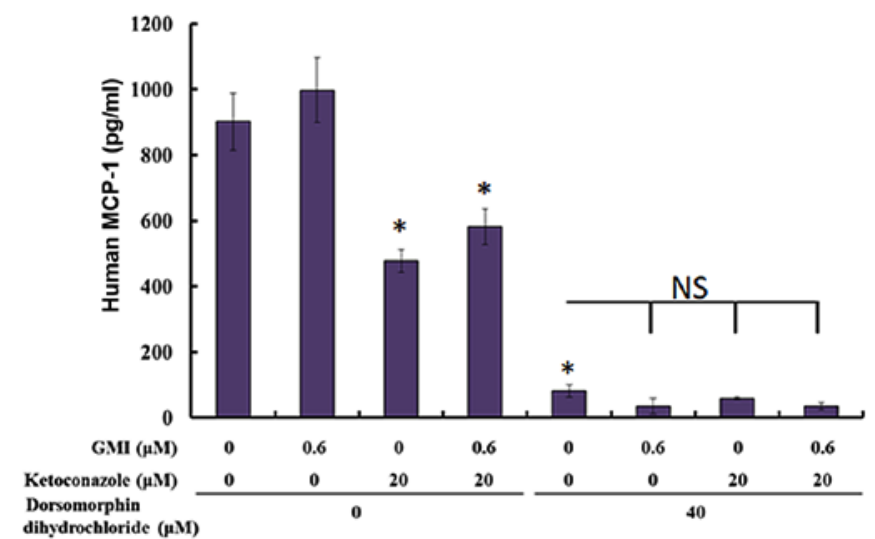

Figure 5. Effects of ketoconazole combined with GMI on the level of MCP-1. A375.S2 cells were pretreated with various concentrations of dorsomorphin dihydrochloride $(0$ or $40 \mu \mathrm{M})$ for $1 \mathrm{~h}$ followed by treatment with ketoconazole $(0$ or $20 \mu \mathrm{M})$ and GMI $(0$ or $0.6 \mu \mathrm{M})$ for $48 \mathrm{~h}$. The conditioned media were then subjected to an enzyme-linked immunoabsorbent assay to measure the levels of secreted MCP-1. Data are presented as the mean \pm standard deviation from three independent experiments. NS, no significance; GMI, Ganoderma microsporum; MCP-1, monocyte chemoattractant protein- $1 .{ }^{~} \mathrm{P}<0.05$ vs. GMI $0 \mu \mathrm{M}$.

MCP-1. In addition, dorsomorphin dihydrochloride significantly reduced the level of MCP-1 (Fig. 5).

\section{Discussion}

Ketoconazole, a cytochrome P450, family 3, subfamily A (CYP3A) inhibitor, promotes androgen receptor (AR) nuclear localization. Inhibition of CYP3A5 has been associated with inhibitory effects in response to dihydrotestosterone treatment in prostate cancer cells by decreasing nuclear AR localization and reducing prostate-specific antigen levels (16). Therefore, co-treatment with CYP3A inhibitor may offer a strategy for improving androgen deprivation therapy (16). A combination of CYP inhibitor and ERK inhibitor enhances anti-colon cancer cell activity (17). Co-administration of CYP3A inhibitor and ketoconazole with the proteasome inhibitor bortezomib has been reported to increase the blood proteasome inhibitory effect in patients with advanced solid tumors by 35\% (18). Ketoconazole also enhances the effect of chemotherapeutic agents, including doxorubicin (19), mitoxantrone (20) and docetaxel (3). Oral delivery of pacitaxel with a dual CYP3A4 inhibitor has been demonstrated to effectively inhibit tumor growth in B16 F10 melanoma tumor-bearing mice (21). The results of the present study supported a therapeutic potential of a combination of ketoconazole and GMI for melanoma treatment.

The AMPK-associated kinase NUAK family SNF1-like kinase 2 exhibits oncogenic properties in melanoma cells during cancer development and tumor progression (22). Metformin blocks melanoma invasion and metastasis via AMPK activation (23). In the current study, GMI was revealed to activate AMPK, which may serve a role in the inhibition of migration. In addition, GMI appeared to have a small effect on the expression of p-ACC. It has been reported that ACC activation occurs via an AMPK-independent pathway (24). GMI triggers the AMPK-dependent and the ACC-independent pathway. 
The BRAF V600E mutation is present in $~ 50 \%$ of all cases of melanoma and oral BRAF inhibitors, including PLX472, inhibit tumors in patients with this mutation via inhibition of the oncogenic mitogen-activated protein kinase signaling pathway (25). Knight et al (25) revealed that treatment with PLX4720 decreases the expression level of MCP-1, which is associated with a decrease in tumor growth. Combination therapy of PLX4720 and anti-MCP-1 has been demonstrated to promote anti-melanoma activity in mouse models (25). In the present study, ketoconazole decreased the expression level of MCP-1, which may lead to antitumor effects. Therefore, ketoconazole may be applied for the treatment of melanoma cases with the BRAF V600E mutation. In conclusion, the current study demonstrated that a combination of ketoconazole with GMI exhibits therapeutic potential against melanoma. Therefore, clinical trials of this combination therapy are required in the future.

\section{Acknowledgements}

Not applicable.

\section{Funding}

The present study was supported by Chung Shan Medical University Hospital, Taiwan (grant nos. CSH-2017-C-015 and CSH-2014-C-023) and the Ministry of Science and Technology, Taiwan (grant nos. MOST 104-2311-B-040-001, MOST 106-2314-B-040-017 and MOST 107-2314-B-040-016-MY2).

\section{Availability of data and materials}

All data generated or analyzed during this study are included in this published article.

\section{Authors' contributions}

YPH and JLK conceived and designed the study. CTL, CTH, YCC and YDL performed experiments and analyzed the data. TYH, PYL and YTK conducted data analysis and interpretation. YPH and JLK wrote, edited and revised the manuscript. All authors discussed results and collaboratively in drafting the manuscript.

\section{Ethics approval and consent to participate}

Not applicable.

\section{Patient consent for publications}

Not applicable.

\section{Competing interests}

The authors declare that they have no competing interests.

\section{References}

1. Lopez-Barcons L, Maurer BJ, Kang MH and Reynolds CP: P450 inhibitor ketoconazole increased the intratumor drug levels and antitumor activity of fenretinide in human neuroblastoma xenograft models. Int J Cancer 141: 405-413, 2017.
2. Agarwal SK, Salem AH, Danilov AV, Hu B, Puvvada S, Gutierrez M, Chien D, Lewis LD and Wong SL: Effect of ketoconazole, a strong CYP3A inhibitor, on the pharmacokinetics of venetoclax, a BCL-2 inhibitor, in patients with non-Hodgkin lymphoma. Br J Clin Pharmacol 83: 846-854, 2017.

3. Figg WD, Woo S, Zhu W, Chen X, Ajiboye AS, Steinberg SM, Price DK, Wright JJ, Parnes HL, Arlen PM, et al: A phase I clinical study of high dose ketoconazole plus weekly docetaxel for metastatic castration resistant prostate cancer. J Urol 183: 2219-2226, 2010.

4. Hsin IL, Ou CC, Wu TC, Jan MS, Wu MF, Chiu LY, Lue KH and Ko JL: GMI, an immunomodulatory protein from Ganoderma microsporum, induces autophagy in non-small cell lung cancer cells. Autophagy 7: 873-882, 2011.

5. Lin $\mathrm{CH}$, Hsiao YM, Ou CC, Lin YW, Chiu YL, Lue KH, Chang JG and Ko JL: GMI, a Ganoderma immunomodulatory protein, down-regulates tumor necrosis factor $\alpha$-induced expression of matrix metalloproteinase 9 via NF- $\kappa \mathrm{B}$ pathway in human alveolar epithelial A549 cells. J Agric Food Chem 58: 12014-12021, 2010.

6. Chiu LY, Hu ME, Yang TY, Hsin IL, Ko JL, Tsai KJ and Sheu GT: Immunomodulatory protein from Ganoderma microsporum induces pro-death autophagy through Akt-mTOR-p70S6K pathway inhibition in multidrug resistant lung cancer cells. PLoS One 10: e0125774, 2015.

7. Hsin IL, Ou CC, Wu MF, Jan MS, Hsiao YM, Lin CH and Ko JL: GMI, an immunomodulatory protein from Ganoderma microsporum, potentiates cisplatin-induced apoptosis via autophagy in lung cancer cells. Mol Pharm 12: 1534-1543, 2015.

8. Wang TY, Yu CC, Hsieh PL, Liao YW, Yu CH and Chou MY: GMI ablates cancer stemness and cisplatin resistance in oral carcinomas stem cells through IL-6/Stat 3 signaling inhibition. Oncotarget 8: 70422-70430, 2017.

9. Hardie DG: AMPK: Positive and negative regulation, and its role in whole-body energy homeostasis. Curr Opin Cell Biol 33: 1-7, 2015.

10. Roy I,McAllisterDM, Gorse E,DixonK,PiperCT,Zimmerman NP, Getschman AE, Tsai S, Engle DD, Evans DB, et al: Pancreatic cancer cell migration and metastasis is regulated by chemokine-biased agonism and bioenergetic signaling. Cancer Res 75: 3529-3542, 2015.

11. Qiao L, Zheng J, Jin X, Wei G, Wang G, Sun X and Li X: Ginkgolic acid inhibits the invasiveness of colon cancer cells through AMPK activation. Oncol Lett 14: 5831-5838, 2017.

12. Kalbasi A, Komar C, Tooker GM, Liu M, Lee JW, Gladney WL, Ben-Josef E and Beatty GL: Tumor-derived CCL2 mediates resistance to radiotherapy in pancreatic ductal adenocarcinoma. Clin Cancer Res 23: 137-148, 2017.

13. Chang AL, Miska J, Wainwright DA, Dey M, Rivetta CV, Yu D, Kanojia D, Pituch KC, Qiao J, Pytel P, et al: CCL2 produced by the glioma microenvironment is essential for the recruitment of regulatory $\mathrm{T}$ cells and myeloid-derived suppressor cells. Cancer Res 76: 5671-5682, 2016.

14. Kim HS, Kim MJ, Kim EJ, Yang Y, Lee MS and Lim JS: Berberine-induced AMPK activation inhibits the metastatic potential of melanoma cells via reduction of ERK activity and COX-2 protein expression. Biochem Pharmacol 83: 385-394, 2012.

15. Gazzaniga S, Bravo AI, Guglielmotti A, van Rooijen N, Maschi F, Vecchi A, Mantovani A, Mordoh J and Wainstok R: Targeting tumor-associated macrophages and inhibition of MCP-1 reduce angiogenesis and tumor growth in a human melanoma xenograft. J Invest Dermatol 127: 2031-2041, 2007.

16. Mitra R and Goodman OB Jr: CYP3A5 regulates prostate cancer cell growth by facilitating nuclear translocation of AR. Prostate 75: 527-538, 2015.

17. Lim SM, Hwang JW, Ahn JB, Bae SK, Park CH, Kim KY, Rha SY, Chung HC, Roh JK and Shin SJ: Combination of CYP inhibitor with MEK/ERK inhibitor enhances the inhibitory effect on ERK in BRAF mutant colon cancer cells. Anticancer Res 33: 2499-2508, 2013.

18. Venkatakrishnan K, Rader M, Ramanathan RK, Ramalingam S, Chen E, Riordan W, Trepicchio W, Cooper M, Karol M, von Moltke L, et al: Effect of the CYP3A inhibitor ketoconazole on the pharmacokinetics and pharmacodynamics of bortezomib in patients with advanced solid tumors: A prospective, multicenter, open-label, randomized, two-way crossover drug-drug interaction study. Clin Ther $31 \mathrm{Pt}$ 2: 2444-2458, 2009.

19. Sella A, Kilbourn R, Amato R, Bui C, Zukiwski AA, Ellerhorst J and Logothetis CJ: Phase II study of ketoconazole combined with weekly doxorubicin in patients with androgen-independent prostate cancer. J Clin Oncol 12: 683-688, 1994. 
20. Eklund J, Kozloff M, Vlamakis J, Starr A, Mariott M, Gallot L, Jovanovic B, Schilder L, Robin E, Pins M and Bergan RC: Phase II study of mitoxantrone and ketoconazole for hormone-refractory prostate cancer. Cancer 106: 2459-2465, 2006.

21. Patel K, Patil A, Mehta M, Gota V and Vavia P: Oral delivery of paclitaxel nanocrystal (PNC) with a dual Pgp-CYP3A4 inhibitor: Preparation, characterization and antitumor activity. Int J Pharm 472: 214-223, 2014.

22. Namiki T, Tanemura A, Valencia JC, Coelho SG, Passeron T, Kawaguchi M, Vieira WD, Ishikawa M, Nishijima W, Izumo T, et al: AMP kinase-related kinase NUAK2 affects tumor growth, migration, and clinical outcome of human melanoma. Proc Natl Acad Sci USA 108: 6597-6602, 2011.
23. Cerezo M, Tichet M, Abbe P, Ohanna M, Lehraiki A, Rouaud F, Allegra M, Giacchero D, Bahadoran P, Bertolotto C, et al: Metformin blocks melanoma invasion and metastasis development in AMPK/p53-dependent manner. Mol Cancer Ther 12: 1605-1615, 2013.

24. Fediuc S, Gaidhu MP and Ceddia RB: Regulation of AMP-activated protein kinase and acetyl-CoA carboxylase phosphorylation by palmitate in skeletal muscle cells. J Lipid Res 47: 412-420, 2006.

25. Knight DA, Ngiow SF, Li M, Parmenter T, Mok S, Cass A, Haynes NM, Kinross K, Yagita H, Koya RC, et al: Host immunity contributes to the anti-melanoma activity of BRAF inhibitors. J Clin Invest 123: 1371-1381, 2013. 